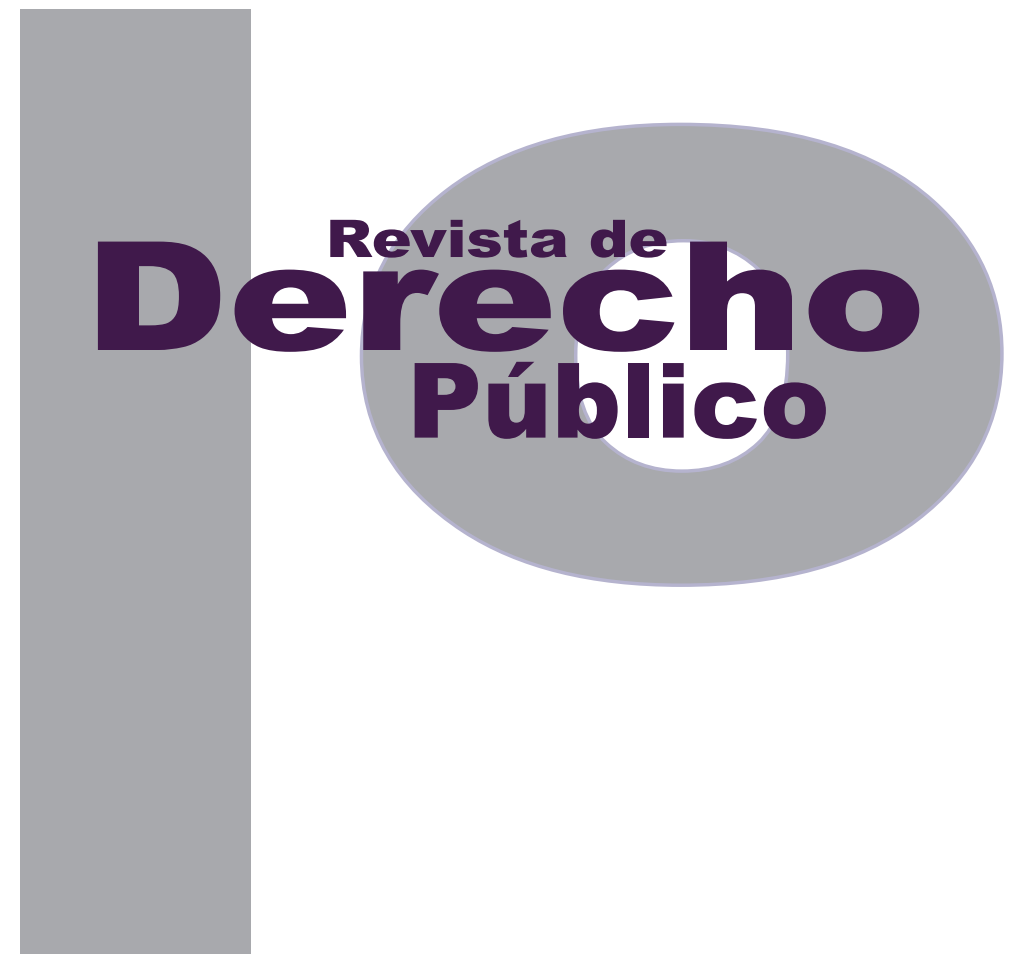

\title{
VIVIENDA DE INTERÉS SOCIAL: EL RESULTADO DEL PRESUPUESTO EQUIVOCADO
}

\author{
LUIS Miguel FALLA ZÚÑIgA
}

Universidad de los Andes

Facultad de Derecho

Revista de Derecho Público N. ${ }^{\circ} 32$

Enero - Junio de 2014. ISSN 1909-7778 


\title{
Vivienda de interés social: el resultado del presupuesto equivocado*
}

\author{
Luis Miguel Falla Zúñiga $^{* *}$
}

\section{RESUMEN}

El modelo político escogido en Colombia para ofrecer vivienda a las familias de menores ingresos involucra al mercado como regulador del acceso efectivo a las unidades de habitación, exclusivamente bajo el paradigma de la propiedad privada. Mientras tanto, constitucionalmente se pretende garantizar el derecho a la vivienda digna como declaración política con dificultades en su materialización. Al mismo tiempo, se abre paso en el escenario internacional el derecho a la ciudad como precepto esencialmente colectivo, dejando al descubierto la discordancia entre la realidad económica del modelo y sus alcances sociales. Este texto, por lo tanto, contrapone los conceptos propiedad privada, utilidad social;
The political model chosen in Colombia to offer public housing to the poorest, involves the market taken as a regulator of the effective access to houses, exclusively following the private property paradigm. Meanwhile, it is intended to constitutionally grant the right to housing ensured also as a political statement. At the same time, the right to the city progressively makes its way into the international scenery as a collective precept; this helps visualize the conflict between the economic reality of the model and its social implications. Therefore, the text contrasts the concepts of private property, social utility; individualism, collectivism; and constitutional framework, supply and demand laws.

Cómo citar este artículo: Falla, L.M. (junio, 2014). Vivienda de interés social: el resultado del presupuesto equivocado. Revista de Derecho Público, 32. Estudiante de Derecho de la Universidad de los Andes. Representante estudiantil por la Facultad de Derecho de la Universidad de los Andes 20122013. Actualmente es Asociado en Martínez Neira Abogados. Correo electrónico: Im.falla435@uniandes.edu.co 
individualismo, colectivismo; y marco constitucional, leyes de la oferta y la demanda.

Palabras Clave: vivienda de interés social, propiedad, derecho a la ciudad, subsidio, vivienda digna, déficit habitacional.
KEY WORDS: public housing, property, right to the city, subsidy. 
SUMARIO

Consideraciones preliminares - I. PARÁMETROS LEGALES CREADORES DEL MODELO DE VIVIENDA DE INTERÉS SOCIAL - II. LA CIUDAD COMO FUENTE PARA EL LOGRO DE OBJETIVOS COLECTIVOS - III. LA ANTÍTESIS DE LA UTILIDAD SOCIAL: LA PROPIEDAD PRIVADA - IV. UNA PERSPECTIVA MÁS AMPLIA DE LA REALIDAD SOCIAL A PARTIR DE LA VIVIENDA SOCIAL - Bibliografía. 


\section{Consideraciones preliminares}

La definición de una línea única de conducta tendiente a solucionar el déficit habitacional, se establece como la piedra angular en la selección de políticas públicas, en procura de seguir el proceso lógico de su ejecución. En efecto, se altera dicha lógica cuando el discurso constitucional, legislativo y de derecho internacional alcanza un desarrollo suficiente en materia de garantía de los derechos fundamentales, que no se corresponde con los intereses y la voluntad de los actores involucrados, al formular sistemas de vivienda inconsistentes con las reales necesidades sociales. Por lo tanto, la divergencia entre las disposiciones legales y los precedentes jurisprudenciales, con los mecanismos económicos contemplados para la ejecución de las políticas públicas de vivienda de interés social, dejan al descubierto una falla estructural en el primer paso natural para darle solución a los altos índices de déficit habitacional: no haber previsto, desde el principio, una conducta general y consensuada entre los diferentes actores activos involucrados en el desarrollo de la política de vivienda de interés social, integrando también al sujeto pasivo de dicha política, es decir, a sus beneficiarios.

Adicionalmente a lo anterior, y como se verá detenidamente más adelante, el actual sistema de vivienda de interés social pretende estimular la demanda de vivienda mediante el otorgamiento de subsidios a las personas de ingresos más bajos. Esto se ha realizado vinculando como actor indirecto al mercado, al tenor de la dinámica de las leyes de la oferta y la demanda, cuyos controles sobre las posibilidades de adquisición de la propiedad excluyen la garantía efectiva del cubrimiento de las necesidades cuantitativas de vivienda. En últimas, la concepción individualista de la propiedad y de los mecanismos económicos y políticos previstos para la vivienda de interés social, riñen con el colectivismo subyacente al principio constitucional de vivienda digna, así como con el reciente desarrollo doctrinal del derecho a la ciudad, el cual se viene abriendo paso en ámbito internacional. Técnicamente, la contradicción se hace aún más evidente cuando el estímulo a la demanda de vivienda de interés social prevalece sobre el estímulo a la oferta de esta, desequilibrando las responsabilidades compartidas asociadas al axioma de solidaridad del Estado Social de Derecho. Lo anterior se explica cuando quienes deben proveerse de los recursos para cubrir el excedente de los subsidios mediante créditos financieros se encuentran en peor posición para lidiar con las leyes del mercado, que los actores que conceden los créditos y construyen las viviendas.

El presente texto tiene por objeto evidenciar la contradicción existente entre la garantía del derecho a la vivienda digna y del derecho a la ciudad como fines constitucionales, y el sistema de vivienda de interés social regulado por las leyes del mercado, el cual funge como intermediario respecto al acceso a vivienda por parte de sus beneficiarios. Para tales efectos, en una primera parte se hará referencia al marco legal que desarrolla y regula la política pública de vivienda de interés social y los derechos 
inherentes o asociados a ella. En segundo lugar, se abordará la propiedad privada desde un punto de vista crítico, analizando su protección frente a los preceptos de justicia social y utilidad colectiva. Por último, se pretende dar una solución general a la contradicción propuesta, bajo el entendido que los instrumentos jurídicos sustanciales plantean una visión colectiva de propiedad, al tiempo que los planes de ejecución funcionan a favor de la rentabilidad y la disminución del riesgo para los actores involucrados, evidenciando así una posición claramente individualista.

\section{PARÁMETROS LEGALES CREADORES DEL MODELO DE VIVIENDA DE INTERÉS SOCIAL}

El artículo 51 de la Constitución Política de CoIombia señala:

Todos los colombianos tienen derecho a vivienda digna. El Estado fijará las condiciones necesarias para hacer efectivo este derecho y promoverá planes de vivienda de interés social, sistemas adecuados de financiación a largo plazo y formas asociativas de ejecución de estos programas de vivienda. ${ }^{1}$

La ubicación doctrinal del derecho a la vivienda digna dentro de los derechos económicos, sociales y culturales, cuya principal característica es su carácter prestacional a cargo del Estado, ha puesto en cabeza del Legislador la responsabilidad de desarrollar un marco normativo que

Constitución Política de Colombia, art. 51. Julio 7 de 1991. programe la asignación de recursos para el cumplimiento efectivo de los derechos involucrados. ${ }^{2}$

En ese orden de ideas, es la Ley $3^{\mathrm{a}}$ de 1991 el inicio del desarrollo legislativo en materia de vivienda de interés social, en cuanto por medio de dicha disposición se establece el Sistema Nacional de Vivienda de Interés Social como el conjunto de acciones, entidades, fines y mecanismos para alcanzar estándares plenos de cubrimiento y calidad en materia de vivienda para las familias de menores ingresos. En efecto, la política de vivienda social establecida en la citada norma plantea como forma de acceso a esta el otorgamiento de subsidios, previa postulación de los sujetos beneficiarios, cuyo valor cubrirá una parte del monto total de cada unidad habitacional, debiendo entonces suplir el excedente con recursos propios o mediante créditos concedidos por entidades financieras con tasas de interés preferenciales y reguladas legalmente. De acuerdo con lo anterior, el artículo $6^{\circ}$ de la Ley $3^{\mathrm{a}}$ de 1991, modificado por el artículo 28 de la Ley 1469 de 2011, preceptúa:

Establézcase el Subsidio Familiar de Vivienda como un aporte estatal en dinero o en especie, que podrá aplicarse en lotes con servicios para programas de desarrollo de autoconstrucción, entre otros, otorgado por una sola vez al beneficiario con el objeto de facilitar el acceso a una solución de vivienda de interés social o interés

2 Corte Constitucional de Colombia. Sentencia T-530 de 2011 (M. P.: Humberto Antonio Sierra Porto, julio 7 de 2011). Sobre el derecho a la vivienda digna: "(...) se trata de un derecho de carácter prestacional cuyo contenido debe ser precisado en forma programática por las instancias del poder que han sido definidas con fundamento en el principio democrático, de conformidad con las condiciones jurídico materiales disponibles en cada momento histórico". 
prioritario de las señaladas en el artículo $5^{\circ}$ de la presente ley, sin cargo de restitución, siempre que el beneficiario cumpla con las condiciones que establece esta ley. ${ }^{3}$

El marco normativo establecido en la Ley $3^{a}$ de 1991 determina un cambio trascendental en la política de vivienda, al incluir a nuevos actores en una estrategia de largo plazo y ubicar al Estado como un participante dual: interviene directamente mediante la contribución que realiza con su política de subsidios sin cargo de restitución, e indirectamente como mero regulador de los participantes de la dinámica de generación de vivienda. El cambio estriba, por lo tanto, en la transición del subsidio a la oferta cuando el Estado era a su vez constructor y responsable del sistema hipotecario, hacia el subsidio a la demanda utilizando los subsidios como incentivos a la adquisición de vivienda cuya oferta depende de la intervención por cuenta propia de entidades financieras y constructoras de carácter privado. De acuerdo con el libro Vivienda social en Colombia: una mirada desde su legislación 1918-2005, coordinado por Olga L. CebaIlos, "La Ley $3^{a}$ del 15 de enero de 1991, es el gran marco político que supone un cambio radical del papel del Estado en materia de vivienda social (...). Esta ley define el nuevo rumbo de la política estatal sobre vivienda y determina las nuevas formas de participación del Estado y del sector privado en la producción habitacional". ${ }^{4}$

3 Ley $3^{\mathrm{a}}$ de 1991. Por la cual se crea el Sistema Nacional de Vivienda de Interés Social, se establece el subsidio familiar de vivienda, se reforma el Instituto de Crédito Territorial, ICT, y se dictan otras disposiciones. Enero 15 de 1991. Diario Oficial no. 39631.

4 CEBALLOS RAMOS, Olga Lucía. (Coord.) Vivienda social en Colombia: una mirada desde su legislación 1918-2005. Bogotá: Pontificia Universidad Javeriana, 2008, p. 265.
Ahora bien, la Ley $3^{a}$ de 1991 , junto con la Ley 1469 de 2011 modificatoria de la primera, plantea un interesante concepto denominado "solución de vivienda". La Ley 1469 de 2011 establece en su artículo 50: "Se entiende por solución de vivienda, el conjunto de operaciones que permite a un hogar disponer de habitación en condiciones sanitarias satisfactorias de espacio, servicios públicos y calidad de estructura, o iniciar el proceso para obtenerla en el futuro". ${ }^{5}$

El mismo artículo, de manera enunciativa, ejemplifica las acciones a emprenderse para obtener soluciones de vivienda, entre las cuales se destacan la construcción o adquisición de vivienda, adquisición de terrenos y lotes para autoconstrucción, y particularmente una que llama nuestra atención para efectos del presente texto: la de celebración de contratos de leasing habitacional.

A excepción del último ejemplo de acciones citado, puede inferirse una interpretación del mandato constitucional encaminada hacia la asociación directa entre la solución al déficit habitacional y la adquisición de propiedad por parte de los beneficiarios de los programas de vivienda de interés social. En otras palabras, la adquisición de dominio de los inmuebles habitacionales y la posibilidad de obtener el título de propiedad, parece ser el mecanismo prevalente y casi exclusivo presente en las disposiciones reglamentarias de vivienda de interés social,

$5 \quad$ Ley 1469 de 2011. Por la cual se adoptan medidas para promover la oferta de suelo urbanizable y se adoptan otras disposiciones para promover el acceso a la vivienda. Junio 30 de 2011. Diario Oficial $\mathrm{n}^{\circ}$. 48116. 
por medio del cual se pretende garantizar el derecho a una vivienda digna. Como correlato de lo anterior, la Ley 546 de 1996 que prescribe al Gobierno Nacional los criterios generales en materia de vivienda y regula sus mecanismos de financiación, establece en su artículo $2^{\circ}$ :

El Gobierno Nacional regulará el sistema especializado de financiación de vivienda de largo plazo para fijar las condiciones necesarias para hacer efectivo el derecho constitucional a la vivienda digna, de conformidad con los siguientes objetivos y criterios:

1. Proteger el patrimonio de las familias representado en vivienda. (...)

2. Promover la construcción de vivienda en condiciones financieras que hagan asequible la vivienda a un mayor número de familias. ${ }^{6}$

Como puede evidenciarse, los programas por medio de los cuales se pretende hacer efectivo el derecho constitucional a la vivienda digna presuponen un sistema de financiamiento dirigido hacia familias individualmente consideradas, quienes al acceder a ellos han previamente aceptado el endeudamiento, para así ingresar a su patrimonio bienes inmuebles cuyo tráfico jurídico está limitado a reglas temporales y legalmente establecidas. ${ }^{7}$ Lo anterior merece

6 Ley 546 de 1999. Por la cual se dictan normas en materia de vivienda, se señalan los objetivos y criterios generales a los cuales debe sujetarse el Gobierno Nacional para regular un sistema especializado para su financiación, se crean instrumentos de ahorro destinado a dicha financiación, se dictan medidas relacionadas con los impuestos y otros costos vinculados a la construcción y negociación de vivienda y se expiden otras disposiciones. Diciembre 23 de 1999. Diario Oficial $\mathrm{n}^{\circ}$. 43827.

$7 \quad$ Establece el artículo $8^{\circ}$ de la Ley $3^{a}$ de 1991: "El Subsidio Familiar de Vivienda será restituible al Estado cuanto el beneficiario transfiera el consideraciones especiales, más aún cuando el carácter prestacional del derecho a la vivienda digna se materializa, de manera más efectiva, cubriendo de manera amplia necesidades insatisfechas de la población en situación de mayor vulnerabilidad, conforme a una visión solidaria, y aún colectiva, del punto de equilibrio que se pretende alcanzar.

\section{LA CIUDAD COMO FUENTE PARA EL LOGRO DE OBJETIVOS COLECTIVOS}

Ahora bien, la colectividad está esencialmente inmersa en el derecho a la ciudad, entendido este último por su gestor, Henry Lefebvre, como “la manifestación de una forma superior de derechos: el derecho a la libertad, a la individualización en socialización, vivir y habitar. El derecho a la obra, a la participación, a la apropiación". En función de una realidad mundial asociada al crecimiento vertiginoso de las ciudades, resultado de la mayor concentración de personas en los centros urbanos, la comunidad internacional ha incrementado sus esfuerzos por desarrollar un ámbito de protección de los derechos derivados de vivir en la ciudad. En consecuencia, se han promulgado distintos instrumentos internacionales en los que ha quedado consignado el derecho a la ciudad, entre ellos la Carta Mundial del Derecho a la Ciudad, propuesta por la Agencia

dominio de la solución de vivienda o deje de residir en ella antes de haber transcurrido cinco años desde la fecha de su asignación, sin mediar permiso específico fundamentado en razones de fuerza mayor definidas por el reglamento."

LEFEBVRE, Henri. Le Droit à la Ville. En: Kofman, E. and Lebas, E. (editores y traductores). Writings on Cities. Oxford: Blackwell Publishing, 1968, [traducción libre]. 
Hábitat de las Naciones Unidas y a la cual han adherido la mayoría de países del mundo. Allí, el referido derecho viene definido como

el usufructo equitativo de las ciudades dentro de los principios de sustentabilidad y justicia social. Se entiende como un derecho colectivo de los habitantes de las ciudades, en especial de los grupos empobrecidos vulnerables y desfavorecidos, que les confiere la legitimidad de acción y de organización, basado en sus usos y costumbres, con el objetivo de alcanzar el pleno ejercicio del derecho a un patrón de vida adecuado. $^{9}$

El discurso asociado al derecho a la ciudad encuentra su origen en reivindicaciones sociales de movimientos políticos y organizaciones no gubernamentales legitimadas por la crítica al sistema neoliberal y a los efectos de la globalización, sobre todo en lo que tiene que ver con la inequidad social, los valores y la participación democrática en las ciudades. ${ }^{10}$

De esta forma, las ciudades han sido proyectadas como centros de desarrollo colectivo, en ejercicio de la función social que les corresponde de acuerdo con la Carta Mundial de Derecho a la Ciudad. Por demás, las ciudades han de ser entendidas necesariamente como entidades de conformación colectiva en cuanto al conjunto de elementos objetivos y subjetivos que las componen. Su función social, por lo tanto, va dirigida

9 UN-Habitat. Carta Mundial de Derecho a la Ciudad. Foro Mundial Urbano. Barcelona - Quito, octubre 2004.

10 BELDA, Sergio et al. Resistance and alternative against the new discourse of the right to the city: the case of the Movimento dos SemTeto da Bahia. Salvador da Bahia, Brazil, 2011. a la garantía de condiciones generales de habitabilidad, de las cuales la propiedad privada es solo un elemento integrante, mas no una prerrogativa para su cumplimiento efectivo. En realidad, la misma Carta Mundial del Derecho a la Ciudad relega la propiedad privada a un segundo lugar en cumplimiento de los objetivos colectivos previstos; al enunciar y desarrollar los principios inherentes al derecho a la ciudad, sobresale la función social de la propiedad, cuyo numeral segundo establece: "2. En la formulación e implementación de las políticas urbanas debe prevalecer el interés social y cultural por sobre el derecho individual de propiedad". ${ }^{11}$

\section{LA ANTÍTESIS DE LA UTILIDAD SOCIAL: LA PROPIEDAD PRIVADA}

La interpretación del mandato constitucional sobre vivienda digna por parte de los gobiernos, a partir de 1991, es arbitraria y restringida al recurrir al derecho de propiedad como el único título idóneo para solucionar el déficit habitacional en términos cuantitativos y cualitativos. No obstante, además de contrariar el espíritu de las normas y principios que subyacen a la vivienda de interés social, la propiedad no encaja perfectamente con los fines de los derechos a la ciudad y la vivienda digna. El Observatorio de derechos económicos, sociales y culturales (Observatorio DESC), en cabeza de Gerardo PisareIlo, lo ha entendido en este mismo sentido, afirmando: "[E]s evidente, en efecto, que el derecho de propiedad y los derechos patrimoniales en

11 UN-Habitat. Ob. cit. 
general, concebidos como derechos absolutos e ilimitados, y desvinculados por tanto de la autonomía personal y colectiva, son a menudo fuente de acumulación de poder y de amenaza para el resto de libertades y derechos fundamentales". ${ }^{12}$

La autorizada doctrina de Arturo Valencia Zea haría la siguiente afirmación en uno de sus primeros textos:

Lo mío y lo tuyo no pueden ser la base con la que se construya un ordenamiento jurídico, especialmente cuando la única interpretación de semejantes expresiones solo tienen validez para justificar un sistema de propiedad privada. Las comunidades humanas tienen que construir y vivir dentro de un nuevo concepto de justicia, que evite la escisión de la sociedad en dos clases sociales opuestas en sus intereses económicos (...). ${ }^{13}$

Desde el principio se aprecia un concepto apremiante en la necesidad de buscar definiciones como puntos de partida a las políticas públicas en materia de vivienda: la justicia. En relación con la referencia anterior, seguiría Valencia Zea: "Para ello es necesario que las riquezas generales $\mathrm{y}$, especialmente, las grandes fuentes de producción social, se encuentren organizadas para el beneficio de todos los miembros de la sociedad y no de una minoría". Lo social de los programas de vivienda previstos para las familias de menores ingresos es ante todo una bús-

12 PISARELLO, Gerardo. Observatorio DESC. Vivienda para todos: un derecho en (de)construcción. El derecho a una vivienda digna y adecuada como derecho exigible. Barcelona: Icaria editorial S. A., 2003, p. 31.

VALENCIA ZEA, Arturo. Origen, desarrollo y crítica de la propiedad privada. Bogotá: Temis S. C. A., 1982, p. 473. queda de justicia social, procurando equiparar condiciones de vida dignas frente a aquellas personas que ya han alcanzado una posición de bienestar, particularmente en términos de habitabilidad.

La atribución de un derecho de propiedad a una familia, sin duda marca una consagración de estabilidad económica y social para esa familia individualmente considerada. La estabilidad estaría dada por la posibilidad de constituir un patrimonio que le permita escalar socialmente, así como la opción de reducir la incertidumbre frente a posibles afectaciones de su derecho que puedan dejar a sus integrantes desamparados y a la intemperie. Sin embargo, al tenor del sentido del presente texto, puede desestimarse una opinión como la anteriormente descrita, a partir de un método de análisis en el cual se sobreponga la estabilidad social por encima de la estabilidad que adquiere el titular del derecho de propiedad. En efecto, la función social de la propiedad desarrollada por la Corte Constitucional utiliza el método contrario, esto es, refiriéndose a su titular. Es decir, los "abusos del derecho" de parte del titular del derecho de propiedad están sujetos a normas de orden público (v. gr. propiedad improductiva); y de manera superficial se hace referencia a la prevalencia del interés general, pero siempre como una limitación al dominio y no como una estrategia de planeación urbana bajo una perspectiva colectiva (v. gr. intereses medioambientales). Así es como las limitaciones del concepto "función social" dejan al descubierto un largo camino en la consecución de los fines de vivienda social 
más cercanos al concepto de utilidad social ${ }^{14}$, cuyo significado y aplicación en materia legislativa aún se relaciona con la prevalencia del individualismo asociado a la propiedad privada.

Así las cosas, por encima de la propiedad privada como presupuesto para hacer efectivo el derecho a la vivienda digna, la necesidad de vivienda en virtud del concepto de justicia y utilidad social debe responder a un fundamento de necesidad de la población menos favorecida. De acuerdo con Pisarello:

una vivienda digna resulta fundamental para la supervivencia y para llevar una vida segura, independiente y autónoma. (...). Su violación hace peligrar el derecho al trabajo, que se torna difícil de buscar, asegurar y mantener. Amenaza el derecho a la integridad física y mental (...). Dificulta el derecho a la educación, a la salud y al libre desarrollo de la personalidad, impracticables en cobijos abarrotados, carentes de las condiciones mínimas de habitabilidad. Menoscaba el derecho a elegir residencia, a la privacidad y la vida familiar, y condiciona incluso los derechos de participación política. ${ }^{15}$

Lo anterior guarda relación estrecha con los derechos inherentes a vivir en una ciudad. Debe, en efecto, advertirse el vínculo existente entre los derechos afectados por la carencia de una unidad habitable en condiciones dignas, y el efecto inequitativo y generador de pobreza que viene con el proceso de urbanización como lo anota Lucas Correa:

14 RODOTÀ, Stefano. El terrible derecho: estudios sobre la propiedad privada. Madrid: Civitas, 1986.

15 PISARELLO, Gerardo. Ob. cit., p. 31. las tendencias globales de urbanización y globalización implican no menos que: la desigualdad estructural en el acceso a los bienes y servicios sociales, la inequidad y las significativas concentraciones de la riqueza. A este panorama se suma la creciente urbanización de la pobreza y el correlativo empobrecimiento de las ciudades, la generalizada división social de la comunidad y las prácticas derivadas de exclusión social. ${ }^{16}$

La conclusión preliminar que genera lo anterior es la posición exclusiva asignada a la propiedad privada, al ser esta entendida como instrumento predilecto para la acumulación de riqueza, como recurso central en el proceso de urbanización y como mecanismo de distinción entre individuos. Respecto del derecho a la ciudad, puede notarse en qué medida entender la vivienda de interés social como una aspiración política alcanzable mediante la adquisición de propiedad, contradice el goce efectivo de derechos colectivos que permitan a posteriori (una vez igualadas condiciones mínimas de existencia), el efectivo desarrollo de planes de vida individuales.

\section{UNA PERSPECTIVA MÁS AMPLIA DE LA REALIDAD SOCIAL A PARTIR DE LA VIVIENDA SOCIAL}

Pues bien, el ámbito colectivo de la vivienda debe ser una prioridad en la formulación de políticas públicas, más aún cuando las necesidades

16 CORREA MONTOYA, Lucas. Algunas reflexiones y posibilidades del derecho a la ciudad en Colombia: Ios retos de la igualdad, la participación y el goce de los derechos humanos en los contextos urbanos. En: Revista Jurídica de la Universidad de Palermo. Octubre, 2010, Año 11, no. 1. 
de la población y los criterios de utilidad social deben guiar los planes de ejecución de dichas políticas. En este sentido lo ha expresado Juan Manuel González, como director del Centro Interdisciplinario de Estudios sobre Desarrollo (CIDER):

Es así como la producción de vivienda ha sido dejada completamente a las leyes de la oferta y la demanda del mercado, fuertemente condicionado por las políticas, los logros y los fracasos del sistema financiero en su conjunto. En este contexto se han dejado de lado los elementos colectivos que cualifican a la vivienda, a pesar de que éstos pesan mucho más en el balance del 'conjunto vivienda digna' que la casa en sí misma (espacio privado) y trascienden la condición de tenencia en propiedad o no de la vivienda. ${ }^{17}$ (He resaltado).

En consecuencia, la evaluación de las políticas públicas formuladas en materia de vivienda debe tener un punto de vista crítico hacia el contenido colectivo de los derechos asociados.

Por consiguiente, si el discurso fundado entorno al derecho a la vivienda tiene una connotación esencialmente colectiva, la materialización del derecho debe hacerse en plural (al menos en principio). En concordancia con lo anterior, la Observación General 4 del Comité de Derechos Económicos, Sociales y Culturales en relación con la habitabilidad como condición para la configuración del derecho a la vivienda digna, estableció: "La vivienda adecuada debe ser asequible a los que tengan derecho. Debe conce-

17 MALDONADO COPELLO, María Mercedes. (Edit.). Reforma urbana y desarrollo territorial. Experiencias y perspectivas de aplicación de las leyes $9^{a}$ de 1989 y 388 de 1997. Bogotá, 2003. derse a los grupos en situación de desventaja un acceso pleno y sostenible a los recursos adecuados para conseguir una vivienda. Debería garantizarse cierto grado de consideración prioritaria en la esfera de la vivienda a los grupos desfavorecidos". 18 (He resaltado). La perspectiva que se propone sitúa a sus primeros y principales interesados dentro de un contexto de replanteamiento del orden lógico de necesidades por suplir. Ello reconoce que las dificultades de acceso a vivienda anteceden a la forma en la cual se garantice o se ejerza efectivamente el derecho en una línea secuencial de prioridades.

Es así como la colectividad se posiciona en el punto de partida de cualquier estrategia de configuración de política pública en materia de vivienda. Lo anterior se reconoce, inclusive, desde una mirada sociológica como la que propone Pierre Bordieu: "sólo es posible romper con las falsas evidencias y los errores inscriptos en el pensamiento sustancialista de los lugares si se efectúa un análisis riguroso de las relaciones entre las estructuras del espacio social y las del espacio físico". ${ }^{19}$ Lo anterior va acompañado de una nueva mirada de desarrollo en el marco de la ciudad contemporánea, siguiendo los pasos del Ilamado "nuevo orden urbano-legal ${ }^{20}$. Sobre

18 NACIONES UNIDAS. Comité de Derechos Económicos, Sociales y Culturales. Observación General 4: El derecho a una vivienda adecuada. Sexto período de sesiones, 1991, UN Doc E-1991-23.

19 BORDIEU, Pierre. La miseria del mundo. Madrid, España: Akal, 1999, p. 119.

20 FERNANDES, Edésio. La construcción del derecho a la ciudad en Brasil. En: La ciudad y el derecho: una introducción al derecho urbano contemporáneo. Mauricio Rengifo y Juan Felipe Pinilla (coord.). Bogotá: Universidad de los Andes, Facultad de Derecho, Editorial Temis, 2012, p. 516. 
dicho orden, se ha establecido que confluyen derechos de carácter colectivo, dentro de los cuales Edésio Fernandes enuncia algunos a modo ilustrativo: "el derecho a la planificación urbana, el derecho social a la vivienda, el derecho a la conservación ambiental, el derecho a capturar la plusvalía y el derecho a la regularización de los asentamientos informales". ${ }^{21}$ Por ende, se hacen urgentes cambios de paradigmas que consideren la colectividad como destinataria de la política pública, y de esa forma pensar en cobertura y calidad al mismo tiempo, llenando los vacíos de déficit habitacional cuantitativo y cualitativo con criterio de utilidad social.

En el sentido de lo anterior, el derecho a la ciudad plantea un escenario bajo el cual todos los habitantes de centros urbanos puedan gozar y aprovechar los recursos que ofrece la ciudad, a partir de su redistribución y en aras de alcanzar niveles plenos de equidad. ${ }^{22}$ Adicionalmente, el derecho a la ciudad se ubica como un contexto general en el cual se desarrollan y se hacen efectivos otros derechos, pues siguiendo a Charlotte Mathivet, el derecho a la ciudad no debe ser entendido como otro derecho humano sino como el derecho a reforzar otros derechos que formalmente ya existen. ${ }^{23}$ Bajo este entendido, es cla-

21 Ibíd.

22 Así lo entienden Mathivet y Sungranyes en el texto Cities for all: "This reformulation of urban life offers more equity, where the majority of inhabitants achieve happiness and solidarity, generating and redistributing the benefits of the city for all". Mathivet, Charlotte y Sungranyes, Ana (eds.). Cities for All: Proposals and Experiences towards the Right to the City. Habitat International Coalition. Santiago de Chile, 2010.

23 MATHIVET, Charlotte. The Right to the City: Keys to Understanding the Proposal for "Another City is Possible". En: Mathivet, Charlotte y Sungranyes, Ana (eds.). Cities for All: Proposals and Experiences towards the Right to the City. Habitat International Coalition. Santiago de Chile, 2010. ro que la vivienda como derecho fundamental abarcado dentro de la perspectiva colectiva del derecho a la ciudad, debe reconocer la participación de sus ejecutores, sus beneficiarios y todos aquellos terceros que como parte de la ciudad les afecta el desarrollo sostenible humano que ocurre solo en condiciones de igualdad material. $Y$ en virtud de la perspectiva de equidad subyacente al derecho a la ciudad, el presupuesto inicial para solucionar el déficit habitacional no debe ser analizar la viabilidad de los proyectos en materia financiera, política o económica.

A la luz de dicho entendimiento, es posible procurar alternativas de solución a una problemática que actualmente ha sido abordada mediante presupuestos contradictorios. Sobre el particular, se plantean dos escenarios complementarios que concretan la aproximación a la vivienda digna en función de la colectividad: (i) acceso a la vivienda mediante derechos reales de uso en contraposición a la vivienda en propiedad; y (ii) vivienda colectiva como mecanismo de aprovechamiento de recursos y espacios bajo parámetros de solidaridad.

En primer lugar, para dotar de contenido el derecho a la vivienda digna, y mediante este la consecución de vida adecuada en ciudad, es necesario que la vivienda se posicione como un bien eminentemente de uso. Así lo confirma Julio Tejedor Bielsa al afirmar que "[l]a vivienda aparece hoy, fundamentalmente, como un bien de uso (...)" ${ }^{24}$ Parafraseando a este autor, la so-

24 TEJEDOR BIELSA, Julio. Régimen jurídico general de la vivienda protegida. En: López Ramón, Fernando (coord.). Construyendo el derecho a la vivienda. Madrid: Marcial Pons, 2010, p. 310. 
ciedad actual le otorga una mayor prioridad a la visión social de la vivienda concibiéndola como un elemento fundamental "para el funcionamiento y desarrollo de la propia sociedad, para la emancipación y la formación de hogares". ${ }^{25}$ Significa lo anterior, que la búsqueda de justicia social a la cual se hacía referencia anteriormente, encuentra en el uso inmediato de la vivienda un mecanismo que ayudaría a superar los obstáculos de desarrollo social. Lo anterior implica, naturalmente, un cambio de mentalidad a partir del cual se beneficien las condiciones básicas de desarrollo humano por encima de paradigmas liberales de propiedad a favor de la posición social o de la apropiación de recursos.

Adicionalmente, la colectividad a la cual se ha hecho referencia concentra necesidades y características distintas en su interior. Es por eso que la propiedad no puede ser entendida como la respuesta exclusiva a situaciones distintas. El uso, por el contrario, se encuentra implícito en la propiedad pero puede también garantizarse por otras vías. Al considerar otras vías como el arrendamiento, se diversifica el portafolio de alternativas de acceso y se concibe la visión social de la propiedad. Los subsidios, sin embargo, no han sido contemplados para estas modalidades de acceso, lo cual no resulta difícil de entender cuando normativamente ni siquiera se han establecido mecanismos de ejecución distintos a la propiedad. Con una adecuada reglamentación, la intervención estatal en materia de arrendamiento para vivienda de interés social, tal y

25 lbíd como se ha venido implementando exitosamente en España ${ }^{26}$ o en Argentina ${ }^{27}$, podría cobijar un número más grande de la población en un sistema de vivienda que podría establecerse como primera opción. En efecto, se anticipan ventajas tales como la posibilidad de estimular la oferta inmobiliaria si fuera el mismo Estado el encargado del recaudo y el desembolso de recursos para los constructores. Se podría asegurar un correlativo flujo de caja favorable para el Estado, que recibe el pago por los cánones y mantiene la propiedad de los bienes inmuebles. Se deben crear los motivos reales para que los actores involucrados confluyan en esta figura ${ }^{28}$; pero mientras para los constructores significaría un asunto de lucro o rentabilidad frente al cual convendría un sistema de volumen, para los destinatarios de vivienda se trataría de una posibilidad real de acceso. El sistema financiero sería un interviniente fundamental para soportar el apalancamiento estatal; pero las garantías de pago estarían cubiertas por las propiedades mismas en cabeza del Estado. Y en relación con los riesgos de incumplimiento, su atenuación estaría marcada por reglas claras de desahucio para los tenedores y listas de elegibles de fácil asignación. Por último, el precio del canon de arrendamiento debería "incidir sobre los

26 En el marco de la crisis inmobiliaria española se fomentó el alquiler como vía de salida, tal y como lo explica Sofía de Salas. Véase SALAS, Sofía de. El arrendamiento en el marco del derecho a la vivienda. En: López Ramón, Fernando (coord.). Construyendo el derecho a la vivienda. Madrid: Marcial Pons, 2010, p. 313.

27 SPROVIERI, Juan Eduardo. Vivienda social en alquiler y movilidad residencial. Buenos Aires: Nobuko, 2010, p. 57.

28

Ibíd. 
ingresos" 29 de sus destinatarios, supliendo las carencias mediante subsidios al arrendamiento.

Aún más, llama la atención que la ley en cuestión trae el leasing habitacional como una alternativa similar al arrendamiento, la cual sin embargo no ha sido puesta en marcha ni siquiera en cuanto a su reglamentación se refiere. En todo caso, dicha figura es interesante pues al uso se sumaría la opción de compra por quien habita la vivienda. En este caso, el leasing habitacional reuniría perfectamente las necesidades particulares de la colectividad a la cual hemos hecho mención, a través de un proceso que habilita el uso y que sugiere la eventual adquisición de dominio. La novedad radica entonces en la posibilidad de garantizar la vivienda a las familias de menores ingresos, al tiempo que la titularidad de los bienes seguiría estando en cabeza de entidades asociativas que podrían reinvertir los excedentes de las cuotas mensuales y de los subsidios en la construcción de más soluciones de vivienda de las cuales se puedan beneficiar cada vez más familias.

En segundo lugar, se sugiere el aprovechamiento de la conformación de comunidades suburbanas para potencializar modelos de convivencia colectivos, solidarios y compartidos. Se trata de implementar el modelo de desarrollo sociocultural múltiple que expone María Cecilia Múnera, en virtud del cual comunidades que comparten significados colaboran recíprocamente basados en prácticas de la vida cotidiana. ${ }^{30}$ Sobre dicha

29 Ibíd. p. 78

30 MÚNERA LÓPEZ, María Cecilia. Resignificar el desarrollo. Medellín: Escuela del Hábitat CEHAP, Universidad Nacional de Colombia, 2007. base, es plausible un sistema en el cual las comunidades convivan en espacios que satisfacen necesidades primarias en relación con la preparación de alimentos, el lavado de la ropa, el cuidado de los niños, solo por ilustrar algunas situaciones diarias.

En función de lo anterior, la necesidad de igualar condiciones de vida ubica a las familias menos favorecidas en el foco de atención de los esfuerzos por otorgar vivienda en condiciones dignas, que permitan el efectivo goce de los derechos fundamentales de las personas involucradas. ${ }^{31}$ Para estas personas que comparten necesidades, la conformación de comunidades se hace imprescindible al momento de evaluar soluciones de vivienda. Una vez conformados dichos grupos de personas en circunstancias homogéneas, será posible combinar espacios individuales y espacios colectivos. En particular, se plantea un proyecto de vivienda social en el cual sus habitantes compartan servicios comunales pero tengan espacios individuales reservados a los aspectos más personales de su cotidianidad (horas de sueño, servicios higiénicos, intimidad familiar y social). En la misma línea de argumentación, la posibilidad de una vivienda colectiva se encuentra presente en literatura vigente de arquitectura, tal y como se extrae del siguiente aparte de los arquitectos españoles Montaner y Muxí: “Es necesario reinterpretar la vivienda más allá del ámbito estrictamente privado, po-

31 La interpretación de Charlotte Mathivet de la Carta Mundial del Derecho a la Ciudad sustenta esta vision desde el punto de vista teórico: "this new right is a collective right of urban dwellers, especially of vulnerable and disadvantaged groups, that legitimizes their action and organization based on their habits and customs, with the aim of achieving the full realization of the right to self determination and an adequate standard of living". 
tenciando las actividades compartidas y comunitarias, su capacidad de relación y mejora de las estructuras urbanas, permitiendo llevar una vida completa (trabajo, educación, cultura, ocio, naturaleza) y evitando la construcción meramente numérica de viviendas". ${ }^{32}$

En últimas, cuando la vivienda de interés social se involucra con la economía de mercado, la posibilidad de vivir la ciudad ya no podría ser concebida como derecho, sino precisamente como una posibilidad, como una expectativa no generalizable, esto mientras a la propiedad se acceda prioritariamente mediante el intercambio de bienes y no mediante su uso. Así las cosas, la garantía del derecho a la vivienda exige la evaluación de las necesidades sociales como prerrogativa para su ejecución. Alejandro Florián Borbón aborda tal planteamiento caracterizando la vivienda como mercancía en contraposición a la vivienda como derecho, apelando a la intervención del Estado "para que con su acción se puedan corregir las conocidas imperfecciones, asimetrías y fallas del mercado y para establecer límites a la propiedad privada de manera que se puedan desarrollar principios implícitos en un enfoque de la vivienda como derecho, como la prelación de los intereses colectivos y públicos sobre los intereses privados (...)". ${ }^{33}$ Restándole protagonismo a la propiedad para favorecer modalidades de arrendamiento o leasing, por ejemplo, es posible enfocar la atención en el espacio habitable

32 MONTANER, Josep María y MUXÍ MARTÍNEZ, Zaida. Reflexiones para proyectar viviendas del siglo XXI. En: De-Arq. 06. Bogotá: Universidad de los Andes, julio de 2010, p. 83.

33 DEFENSORÍA DEL PUEBLO-FEDEVIVIENDA. Derecho a una vivienda adecuada desde la perspectiva de los derechos humanos-Memorias en curso. Bogotá: autor, 2007, p. 33. a partir del cual se potencie el adecuado desarrollo humano. Sin cambios en los paradigmas vigentes, el derecho a la vivienda digna estaría cediendo ante la garantía del derecho a la propiedad privada.

\section{Bibliografía}

BAÑO LEÓN, José María. Derecho urbanístico común. Madrid: Editorial lustel, 2009.

BELDA, S., PERIS, J., FREDIANI, A., BONI, A. Resistance and alternative against the new discourse of the right to the city: the case of the Movimento dos SemTeto da Bahia (Salvador da Bahia, Brazil). Edición sin publicar; acceso con autorización del autor.

BORDIEU, Pierre. La miseria del mundo. Madrid, España: Akal, 1999.

CEBALLOS, Olga Lucía (coord.). Vivienda social en Colombia: una mirada desde su legislación 1918-2005. Bogotá: Pontificia Universidad Javeriana, Facultad de Arquitectura y Diseño, 2008.

CENTRO DE ESTUDIOS DE LA CONSTRUCCIÓN Y EL DESARROLLO URBANO Y REGIONAL (CE$N A C)$. Evolución del déficit habitacional en Colombia 1993-2005. [En línea]. Recuperado desde: www.cenac.org.co, 2005.

CHIAPPE DE VILLA, María Luisa. La política de vivienda de interés social en Colombia en los noventa. [En línea]. Santiago de Chile: CEPAL, Naciones Unidas, 1999. Recuperado desde: www.eclac.cl. 
CORREA MONTOYA, Lucas. Algunas reflexiones y posibilidades del derecho a la ciudad en Colombia. Los retos de la igualdad, la participación y el goce de los derechos humanos en Ios contextos urbanos. En: Revista Jurídica de la Universidad de Palermo. Octubre de 2010, año 11, edición 1.

\section{DEFENSORÍA DEL PUEBLO-FEDEVIVIENDA. Dere-}

cho a una vivienda adecuada desde la perspectiva de los derechos humanos-Memorias en curso. Bogotá: autor, 2007.

FERNANDES, Edésio. La construcción del derecho a la ciudad en Brasil. En: Mauricio Rengifo y Juan Felipe Pinilla (coord.). La ciudad y el derecho: una introducción al derecho urbano contemporáneo. Bogotá: Universidad de los Andes, Facultad de Derecho - Editorial Temis, 2012.

HARRIS, J. W. Property and Justice. Oxford: Oxford University Press, 1996.

LEFEBVRE, Henri. Le Droit á la Ville. En: Kofman, E. and Lebas, E. (eds. y tr.). Writingson Cities. Oxford: Blackwell Publishing, 1968.

LÓPEZ RAMOS, Fernando (coord.). Construyendo el derecho a la vivienda. Madrid: Marcial Pons, 2010.

MALDONADO COPELLO, María Mercedes (ed.). Reforma urbana y desarrollo territorial: experiencias y perspectivas de aplicación de las leyes 9a de 1989 y 388 de 1997. Bogotá, 2003.
MATHIVET, Charlotte y SUNRANYES, Ana (eds.). Cities for All: Proposals and Experiences towards the Right to the City. Santiago de Chile: Habitat International Coalition, 2010.

MINISTERIO DE DESARROLLO ECONÓMICO. DIRECCIÓN GENERAL DE VIVIENDA. Vivienda de Interés Social. Marco Legal. Bogotá: autor, 2001.

MONTANER, Josep María y MUXÍ MARTÍNEZ, Zaida. Reflexiones para proyectar viviendas del siglo XXI. En: DeArq. 06. Bogotá: Universidad de los Andes, julio de 2010.

MÚNERA LÓPEZ, María Cecilia. Resignificar el desarrollo. Medellín: Escuela del Hábitat (CEHAP), Universidad Nacional de Colombia, 2007.

ONU. COMITÉ DE DERECHOS ECONÓMICOS SOCIALES Y CULTURALES. Observación General 4. El derecho a una vivienda adecuada. Sexto período de sesiones, 1991. UN Doc E-199123.

ONU-HABITAT. Oficina Regional para América Latina y el Caribe. Estado de las ciudades de América Latina y el Caribe. Rio de Janeiro: autor, 2010.

UN-HÁBITAT. Carta Mundial de Derecho a la Ciudad. Foro Mundial Urbano. Barcelona, Quito. Octubre 2004.

PISARELLO, Gerardo (coord.). Vivienda para todos: un derecho en (de)construcción. Barcelona: Icaria, 2003. 
RODOTÀ, Stefano. El terrible derecho: estudios sobre la propiedad privada. Madrid: Civitas, 1986.

SALAS, Sofía de. El arrendamiento en el marco del derecho a la vivienda. En: López Ramón, Fernando (coord.). Construyendo el derecho a la vivienda. Madrid: Marcial Pons, 2012.

SPROVIERI, Juan Eduardo. Vivienda social en alquiler y movilidad residencial. Buenos Aires: Nobuko, 2010.

TEJEDOR BIELSA, Julio. Régimen jurídico general de la vivienda protegida. En: López Ramón, Fernando (coord.). Construyendo el Derecho a la Vivienda. Madrid: Marcial Pons, 2012.

VALENCIA ZEA, Arturo. Origen, desarrollo y crítica de la propiedad privada. Bogotá: Temis S. C. A., 1982.

\section{Normativa}

COLOMBIA. CONGRESO DE LA REPÚBLICA. Ley $3^{a}$ (15 de enero de 1991). Por la cual se crea el Sistema Nacional de Vivienda de Interés Social, se establece el subsidio familiar de vivienda, se reforma el Instituto de Crédito territorial, ICT, y se dictan otras disposiciones. Diario Oficial no. 39.631.

COLOMBIA. CONGRESO DE LA REPÚBLICA. Ley 388 (18 de julio de 1997). Por la cual se modifica la Ley $9^{a}$ de 1989 y la Ley $3^{a}$ de 1991 y se dictan otras disposiciones. Diario Oficial no. 43.091.
COLOMBIA. CONGRESO DE LA REPÚBLICA. Ley 546 (23 de diciembre 1999). Por la cual se dictan normas en materia de vivienda, se señalan los objetivos y criterios generales a los cuales debe sujetarse el Gobierno Nacional para regular un sistema especializado para su financiación, se crean instrumentos de ahorro destinado a dicha financiación, se dictan medidas relacionadas con los impuestos y otros costos vinculados a la construcción y negociación de vivienda y se expiden otras disposiciones. Diario Oficial no. 43.827.

COLOMBIA. CONGRESO DE LA REPÚBLICA. Ley 1469 (30 de junio de 2011). Por la cual se adoptan medidas para promover la oferta de suelo urbanizable y se adoptan otras disposiciones para promover el acceso a la vivienda. Diario Oficial no. 48.116.

COLOMBIA. CONGRESO DE LA REPÚBLICA. Ley 708 (29 de noviembre de 2001). Por la cual se establecen normas relacionadas con el Subsidio Familiar para Vivienda de Interés Social y se dictan otras disposiciones. Diario Oficial no. 44.632 .

COLOMBIA. CORTE CONSTITUCIONAL. Sentencia C-244 de 2011. M. P.: Juan Carlos Henao Pérez.

COLOMBIA. CORTE CONSTITUCIONAL. Sentencia C-904 de 2011. M. P.: Gabriel Eduardo Mendoza Martelo. 
COLOMBIA. CORTE CONSTITUCIONAL. Sentencia

T-363 de 2004. M. P.: Clara Inés Vargas Hernández.
COLOMBIA. CORTE CONSTITUCIONAL. Sentencia T-530de 2011. M. P.: Humberto Antonio Sierra Porto. 